\title{
LEITURA(S) E LETRAMENTO CRÍTICO: UMA INVESTIGAÇÃO NO ENSINO FUNDAMENTAL I DE UMA ESCOLA INTERNACIONAL
}

\section{Reading(s) and Critical Literacy: an Investigation in the Junior School of an International School}

\author{
Samara de Cássia Rodrigues MARREIRO - USP ${ }^{11}$
}

\section{RESUMO:}

O presente trabalho baseia-se em uma pesquisa de iniciação científica realizada em formato de Trabalho de Graduação Individual (TGI). A pesquisa investigou as construções de sentido de alunos a respeito de suas leituras de livros paradidáticos em língua inglesa, no ensino fundamental I de uma escola internacional na cidade de São Paulo sob a perspectiva das teorias dos multiletramentos e letramento crítico. A partir de uma investigação de cunho etnográfico, o corpus selecionado para análise foram resenhas escritas por esses alunos a respeito da leitura dos livros. Os principais autores que embasam as análises são: Luke, Freebody (1997), Gee (1997), Cope, Kalantzis (2000), Cervetti, Pardales, Damico (2001), entre outros.

PALAVRAS-CHAVE: Letramento crítico; leitura crítica; multiletramentos; leitura; construção de sentidos.

\begin{abstract}
:
This paper is based on a scientific initiation research held in the format of Individual Graduate Paper (TGI). The research investigated the students' process of meaningmaking in the junior school of an international school in the city of São Paulo from the perspective of critical literacies and multiliteracies theories. This is an ethnographictype investigation, whose corpus selected for analysis consists of book reviews about students daily reading books. The main authors that support the analysis are: Luke, Freebody (1997), Gee (1997), Cope, Kalantzis (2000), Cervetti, Pardales, Damico (2001), among others.
\end{abstract}

KEY WORDS: Critical literacy; critical reading; multiliteracies; reading; meaning making.

\section{CONSIDERAÇÕES INICIAIS}

O trabalho que segue discorre sobre uma investigação realizada durante uma pesquisa de iniciação científica, no contexto de trabalho da pesquisadora. Na busca por interpretar as práticas de leituras de alunos de uma turma de quinto ano (antiga quarta série) do ensino fundamental I, a pesquisadora propõe análises a respeito das

\footnotetext{
${ }^{11}$ Mestranda pelo departamento de Estudos Linguísticos e Literários em Inglês, FFLCH, USP. Professora Titular do Brazilian International Integration School.
} 
construções de sentido decorrentes das leituras de livros paradidáticos (doravante reading books) dos alunos registradas na forma de resenhas (doravante book reviews).

A metodologia de pesquisa adotada pauta-se em análises qualitativas, de cunho etnográfico, segundo as bases teóricas interpretativas de Geertz (1978). Segundo este autor, os dados analisados não são uma mera descrição do que se pode apreender pela observação, mas interpretações a respeito dos significados construídos pelos participantes da pesquisa. Outra característica da etnografia, apontada por Geertz (1978), é que ela é microscópica, ou seja, ela trata de maneira extensiva contextos específicos, circunstanciais. E as interpretações e análises advindas desses contextos não buscam generalizações para um contexto mais amplo, mais geral, mas para sua amplitude de possibilidades. Ainda a respeito da investigação de cunho etnográfico, a pesquisadora André (1995) nos lembra que esse tipo de pesquisa deve se voltar para os valores, as concepções e os significados culturais dos atores pesquisados, assim, devemos lembrar que nosso objeto de estudo são na verdade, sujeitos, e que as interpretações geradas nas análises devem advir de diferentes perspectivas e de um certo distanciamento, ou estranhamento com relação a esses dados, o que não significa que haverá neutralidade nas análises. Baynham (2004), por sua vez, chama atenção para a relevância da investigação de cunho etnográfico aos estudos dos letramentos uma vez que não focaliza apenas o ambiente escolar, mas considera as manifestações de letramento em todo o contexto social.

Assim, a partir de uma metodologia interpretativista e tomando as teorias dos multiletramentos e letramento crítico como aportes teóricos, a pesquisa aponta para as mudanças e transformações sociais preconizadas pelos estudiosos dos multiletramentos, o que têm gerado transformações nas maneiras de comunicação e nos diferentes usos da linguagem, como a escrita e leitura. Diante desse contexto, chama-se a atenção para uma (re)significação do papel que a leitura desempenha ou pode desempenhar no letramento escolar, e ainda sobre o que se entende por ler criticamente, a partir de um contraponto teórico entre letramento crítico e leitura crítica.

\section{MULTILETRAMENTOS}

Nos estudos sobre multiletramentos, os pesquisadores do The New London Group propõem expandir a compreensão sobre o que se entende por letramento, o que inclui uma negociação da multiplicidade de discursos, levando em conta as diversidades 
culturais e linguísticas que se tornaram cada vez mais evidentes na sociedade digital e globalizada (COPE e KALANTZIS, 2000). Os autores defendem que a crescente variedade de formatos de textos que circulam associados com informação e multimídias tecnológicas, como imagens, vídeos, áudios, além dos textos impressos, devam ser considerados nos estudos de letramento.

As transformações apontadas pelos estudiosos dos multiletramentos estão intrinsicamente ligadas à mudanças nas esferas pública, privada, assim como no âmbito profissional da vida das pessoas. De maneira geral, os autores chamam a atenção para as grandes mudanças que vêm ocorrendo na economia global, o que tem exigido um novo tipo de trabalhador, mais especializado, diferente daquele da produção em massa do "velho" capitalismo. O antigo modo verticalizado das linhas de produção tem sido, cada vez mais, substituído pela horizontalidade das relações de equipe de trabalho. O trabalhador de agora, deve ser multi, saber sobre todo o processo, ser flexível, e capaz de realizar trabalhos complexos e integrados. Tais premissas ao mesmo tempo que são demandas de propósitos neoliberais capitalistas em prol da eficiência econômica, têm exigido uma participação mais ativa do indivíduo, que deve estar apto a tomar decisões e lidar com situações imprevistas.

Desse modo, levando em conta tais mudanças no âmbito profissional, considera-se uma premissa que os alunos tenham a oportunidade de desenvolver as habilidades requeridas para ter acesso a essa nova linguagem do trabalho e, ainda, desenvolver a capacidade de se fazer ouvir, de negociar, e de ser apto a se envolver criticamente dentro de suas condições de trabalho e vida social. Na esfera educacional, essas mudanças podem contribuir possibilitando uma transição do modo reprodutivo de estruturas de comando e controle tradicionais por relações pedagógicas mais dinâmicas e significativas (COPE e KALANTZIS, 2000).

Na esfera pública, por sua vez, os estudos dos multiletramentos apontam para uma mudança no que se refere ao cívico, ou seja, a noção de cidadania têm mudado. De modo geral, o termo "cívico" têm sido disseminado dentro de uma perspectiva nacionalista e monocultural, que valoriza padrões de língua e cultura em detrimentos de diferenças culturais e dialetos, por exemplo. Nesse sentido, os autores afirmam:

"Os estados intervencionistas em expansão nos séculos dezenove e vinte utilizaram as instituições escolares como maneiras de padronizar as línguas nacionais. No Velho Mundo isso significou impor padrões nacionais sobre diferentes dialetos. No Novo Mundo isso significou 
assimilar povos indígenas e imigrantes aos padrões "apropriados" da língua do colonizador." (p.14) ${ }^{12}$

No entanto, considerando que o civismo não tem sido mais praticado no seu sentido apenas nacionalista tradicional - que prevê uniformidade de valores nacionais, padrões de identidade e cultura, por exemplo - os autores advogam por uma visão de pluralidade cívica que possa arbitrar as diferenças. No âmbito pedagógico isso significa aproveitar diferenças culturais e linguísticas, para que sejam usadas tão fortemente como recursos de aulas assim como são recursos sociais na formação de novos espaços cívicos e novas noções de cidadania.

Há ainda, uma terceira esfera da vida humana que também sofre grandes influências dos aspectos discutidos acima, a esfera privada. $\mathrm{O}$ que se tem observado é uma invasão cada vez maior do espaço privado pelos meios de comunicação em massa, redes de comunicação e informação, dentre outros. Nesse contexto, muitos professores sentem que cada vez mais suas vozes perdem poder em relação às vozes das narrativas globais. Um fator que se destaca nesse contexto é a percepção de que as pessoas, cada vez mais, fazem parte de esferas múltiplas - diversas comunidades estão se estabelecendo sem fronteiras definidas, podendo ser comunidades virtuais, de interesses variados, como orientação sexual, etnia, trabalho, e outros -, então suas identidades possuem camadas múltiplas que se estabelecem por meio de complexas relações umas com as outras. Tais diferenças carregam linguagens, discursos e registros também variados e distintos (COPE e KALANTZIS, 2000).

Os pesquisadores dos multiletramentos reconhecem que um novo tipo de sociedade está emergindo e que a construção de significados e uso da linguagem podem ir além de formas fixas e padronizadas, em prol de valores e perspectivas plurais. Eles indicam novas demandas de ensino para a sociedade digital:

\footnotetext{
"o papel da pedagogia é desenvolver uma epistemologia do pluralismo que oferece acesso sem que as pessoas tenham que apagar ou deixar pra trás diferentes subjetividades. Isso deve ser a base da nova norma" ${ }^{13}$ (op.cit, p.18)
}

Assim, diante da nova sociedade digital, e assumindo que a escola é responsável por regular diversas relações na sociedade, a pedagogia para o letramento encontra um grande desafio a frente. Se antes a escola, por diversas razões, tinha o papel de homogeneizar diferenças na sociedade, agora essa mesma escola se encontra diante de

\footnotetext{
12 Tradução minha.

${ }^{13}$ Tradução minha.
} 
uma multiplicidade que pode ser a parte central de sua pedagogia. Há uma diversidade produtiva, uma pluralidade cívica e uma vida privada multifacetada na sociedade atual que dificilmente a instituição escolar conseguirá ignorar. Neste contexto, espera-se que o letramento escolar desenvolva uma epistemologia da pluralidade, ampliando acesso às diferentes subjetividades, levando em conta as diferentes linguagens, discursos, registros, e usando-os como recursos para o aprendizado, aumentando assim o acesso às novas possibilidades de prática social.

\section{LEITURA CRÍTICA E LETRAMENTO CRÍTICO}

Diante desse contexto de mudanças na sociedade, de novas maneiras de comunicação, interações online pela internet, redes sociais, comunicação multimodal, transformações nas relações de trabalho e nas formas de participação social, como fica a questão da leitura no âmbito escolar? Os alunos leem da mesma maneira que liam algumas décadas atrás? Como o ensino de leitura colabora para a formação de cidadãos críticos e atuantes na sociedade? Mas, afinal, o que se entende por leitores críticos?

Ao buscar investigar as maneiras críticas com que os alunos-participantes da pesquisa pudessem estar lendo os livros paradidáticos de leitura obrigatória, deparei-me com questões como: qual a noção de crítica que pressuponho nas análises dos dados? É possível que alunos de fundamental I possam ler criticamente? E ao buscar respostas para essas questões, os estudos realizados me direcionaram para a percepção de que ler criticamente constrói-se de maneiras diferentes nas perspectivas da leitura crítica e do letramento crítico. O quadro a seguir discorre sobre tais diferenças.

\begin{tabular}{|c|c|c|}
\hline Área & Leitura Crítica & Letramento Crítico \\
\hline Conhecimento & $\begin{array}{l}\text { Conhecimento - por meio de } \\
\text { experiência sensorial e } \\
\text { raciocínio. } \\
\text { Fatos-realidade } \\
\text { Distinguem-se os fatos } \\
\text { (objetivos) das inferências e } \\
\text { julgamentos (subjetivos) do } \\
\text { leitor. }\end{array}$ & $\begin{array}{l}\text { Conhecimento - não é natural ou } \\
\text { neutro. Conhecimento - baseia-se em } \\
\text { regras discursivas de cada comunidade } \\
\text { Logo, o conhecimento é ideológico. }\end{array}$ \\
\hline Realidade & $\begin{array}{l}\text { Pode ser conhecida } \\
\text { Serve como referência para }\end{array}$ & $\begin{array}{l}\text { Não há um conhecimento definitivo } \\
\text { para a realidade. } \\
\text { A realidade não pode ser "capturada" }\end{array}$ \\
\hline
\end{tabular}




\begin{tabular}{|l|l|l|}
\hline & interpretação. & $\begin{array}{l}\text { pela linguagem. } \\
\text { A “verdade" não pode ser definida } \\
\text { numa relação de correspondência com } \\
\text { a realidade; deve ser compreendida em } \\
\text { um contexto localizado. }\end{array}$ \\
\hline Autoria & $\begin{array}{l}\text { Detectar as intenções do autor } \\
- \text { base para os níveis mais } \\
\text { elevados da interpretação } \\
\text { textual. }\end{array}$ & $\begin{array}{l}\text { O significado é sempre múltiplo, } \\
\text { contestável, construído cultural e } \\
\text { historicamente, considerando as } \\
\text { relações de poder. }\end{array}$ \\
\hline Educação & $\begin{array}{l}\text { Desenvolvimento de níveis } \\
\text { elevados de compreensão e } \\
\text { interpretação. }\end{array}$ & Desenvolvimento de percepção crítica. \\
\hline
\end{tabular}

Fonte: Em português: Orientações Curriculares para o Ensino Médio-Línguas Estrangeiras; quadro traduzido de CERVETTI, G.; PARDALES, M. J.; DAMICO ${ }^{14}$

Segundo Cervetti, Pardales e Damico (2001), a visão de leitura advinda da tradição humanista-liberal (décadas de 1950-60) entende que as intenções contidas em um texto podem ser inferidas pelo leitor, pois refletem uma realidade que pode ser conhecida e serve, portanto, como referência à interpretação. Nessa visão, há uma separação entre fatos da realidade e as inferências e julgamentos que o leitor pode fazer a respeito desses fatos. Para isso, a leitura crítica pauta-se no pensamento que é eminentemente racional, deliberado, ordenado, crítico e com um propósito; esse pensamento pode ser diferenciado do pensamento comum diário, que é informal e menos deliberativo. Nessa concepção de crítica, o leitor precisa desenvolver altos níveis de compreensão e interpretação a fim de tornar-se crítico, entendendo que esta é uma etapa final do processo.

Para que isso ocorra, a leitura crítica pressupõe o desenvolvimento de habilidades que incluem: investigação das fontes, reconhecimento do propósito do texto (por que foi construído daquela maneira), a distinção entre opinião e fato, e a realização de inferências e julgamentos do leitor. A maneira apropriada de interpretar determinado texto estaria associada à tentativa de identificar a intenção do autor, pois se supõe

\footnotetext{
${ }^{14}$ Orientações Curriculares para o Ensino Médio-Línguas Estrangeiras; quadro traduzido de CERVETTI, G.; PARDALES, M. J.; DAMICO, J. S. A Tale of Differences: Comparing the Traditions, Perspectives, and Educational Goals of Critical Reading and Critical Literacy. Reading Online. Acesso: April, 2001, http://www.readingonline.org/articles/art_index.asp?HREF=article/cervetti/index.html
} 
filosoficamente que a interpretação correta pode ser distinguida da incorreta, que a realidade pode ser distinguida da ficção. Nessa perspectiva, entende-se que é possível revelar ou desvelar as verdades de um texto. Para tanto, um leitor deve passar por um longo processo de aprendizagem de leitura, para enfim, alcançar níveis elevados de compreensão e interpretação, o que requer muito anos de escolaridade.

O letramento crítico, por sua vez, concebe leitura como prática social crítica que faz uso do texto como um meio de construção e reconstrução de significados (LUKE e FREEBODY, 1997). A leitura é feita nos espaços públicos e privados e está ligada às relações políticas e de poder da vida diária nas culturas letradas. No letramento crítico, a abordagem ao texto é feita por meio de um processo de construção de sentido em que os significados do texto são construídos pelo leitor dentro de um contexto social, histórico e de relações de poder específicos. Essa perspectiva leva a compreender que a leitura ajuda o sujeito não só a entender o mundo, mas é também um meio de transformação social.

Luke e Freebody traçam o surgimento do conceito de letramento crítico a diversos outros estudos como os da linguagem crítica (ex., Gee, 1996; Halliday \& Martin, 1993), da sociologia educacional (ex., Baker \& Luke, 1991), da etnografia e antropologia social (ex., Street, 1984, 1995), do feminismo (ex., Lee, 1996; Luke \& Gore, 1994), da teoria crítico-social (Freire, 1970) - e ainda, de teorias pósestruturalistas (ex., Kamler, 1994; Lemke, 1995). Tais aportes teóricos tão diversos partilham duas acepções comuns importantes. Primeiramente, que práticas sociais de leitura desenvolvidas no contexto escolar constituem seleções de práticas, e tais seleções não são acidentais, aleatórias ou ainda, idiossincráticas. Ao contrário, elas contribuem para as necessidades organizacionais da instituição escolar e aos interesses estratificados dentro da organização social. Assim, os materiais produzidos pelas instituições escolares não são, como possa parecer, elementos "naturais" e "essenciais" ao letramento escolar, contudo, tais materiais e práticas interativas de ensino de leitura podem servir como elementos chaves em que discursos culturais, ideologias políticas e interesses econômicos são transmitidos, transformados, e também contestados.

Quanto ao papel do professor no ensino de leitura na perspectiva do letramento crítico, pode-se dizer que é o de tomar decisões a respeito de como e com qual finalidade deve-se moldar o letramento na cultura contemporânea, fruto de um capitalismo exacerbado, e ainda, como e com qual finalidade deve-se influenciar o desenvolvimento de cidadãos letrados e trabalhadores. $\mathrm{O}$ ensino de leitura, por meio do 
letramento crítico deve vir seguido do ensino de modos culturais de observar, descrever e explicar. O leitor crítico, diante dessa perspectiva, deve compreender discursos, ideologias, valores, representações textuais, posicionando-se diante dos textos, ampliando suas visões de mundo, e compreendendo que a leitura está relacionada com distribuição de conhecimento e poder dentro de uma sociedade.

Dessa maneira, os estudos de letramento crítico procuram possibilitar ao leitor reconhecer que os textos são representações da realidade e que essas representações são construídas socialmente. Uma vez reconhecido isso, tais leitores possuem uma maior oportunidade de tomar uma posição forte em relação a determinado texto, a rejeitá-lo se preciso for, reconstruí-lo de forma que se tornem mais consistentes com suas próprias experiências com o mundo.

Assim, os estudos a respeito do que se entende por crítico, no âmbito educacional, a partir das duas perspectivas apontadas por Cervetti et al, levou a pesquisadora à percepção que não há textos críticos (e outros não-críticos), mas sim, diferenças nas maneiras de abordagem de um texto e, em termos educacionais, nos modos de desenvolver uma crítica à determinado texto. No caso da teoria da leitura crítica, apreende-se a crítica a partir de níveis elevados de interpretação e entendimento dos modos de produção e significação de um texto, ou seja, tornam-se necessários anos de escolarização e leitura para que um leitor se torne crítico. O letramento crítico, por sua vez, atenta para a relação social entre texto e leitor, pois tanto o autor quanto o leitor são produtores de textos e construtores de significação através da linguagem. Para Menezes de Souza (2011), ler criticamente na perspectiva do letramento crítico implica nesses dois papéis que são simultâneos:

\footnotetext{
"Ler criticamente implica em desempenhar pelo menos dois atos simultâneos e inseparáveis: (1) perceber não apenas como o autor produziu determinados significados que tem origem em seu contexto e pertencimento sóciohistórico, mas ao mesmo tempo, (2) perceber como, enquanto leitores, a nossa percepção desses significados e de seu contexto sócio-histórico está inseparável de nosso próprio contexto sócio-histórico e os significados que dele adquirimos ${ }^{15} . "($ p.132)
}

Destarte, a pesquisa de leitura realizada no ensino fundamental I que será apresentada a seguir pautou-se na perspectiva do letramento crítico, considerando, principalmente, dois pontos importantes: (1) o papel ativo do leitor que é construtor de significado, implicado em seu próprio contexto histórico-social, (2) o fato do letramento

\footnotetext{
${ }^{15}$ Grifo como no original.
} 
crítico poder ser colocado em prática, não apenas com salas de ensino universitário, mas para qualquer tipo de leitor, até mesmo nos níveis mais elementares (LUKE, 1994).

\section{O CONTEXTO DE PESQUISA: UMA ESCOLA INTERNACIONAL}

A pesquisa em questão foi realizada em uma escola privada internacional britânica, localizada na cidade de São Paulo, onde a pesquisadora trabalhava como assistente de classe. A escola recebe alunos de diversas nacionalidades, tendo no momento da pesquisa, aproximadamente 23 nacionalidades diferentes, majoritariamente, brasileira. $\mathrm{O}$ recorte da pesquisa investigou alunos de uma classe de quinto ano (antiga quarta série) de ensino fundamental I, com idades entre 9 e 11 anos. Nesse contexto, os alunos são alfabetizados primeiramente em inglês e a língua predominantemente usada na escola é a inglesa. Foram analisados os book reviews produzidos pelos alunos a partir de suas leituras de reading books. Tais livros fazem parte de um esquema nivelado de leitura diária (reading scheme) que visa o desenvolvimento e aprimoramento da fluência em língua inglesa. Os alunos são alocados, pela escola, por níveis ${ }^{16}$ e conforme cumprem as leituras, ou seja, leem uma determinada quantidade de livros requeridos para certo nível, são considerados aptos a prosseguir ao nível seguinte. É importante salientar que a professora é responsável por realocar ou manter um aluno em determinado nível de leitura, se achar necessário, e ainda, nivelar alunos novos ao nível de leitura que julgar apropriado. Como o reading scheme é importado da Inglaterra pela escola, segundo seu nivelamento naquele país, alunos de quinto ano deveriam estar lendo os livros de níveis 12 e 13 . No entanto, no contexto brasileiro da escola internacional, os alunos de quinto ano investigados estavam lendo desde o nível 07 ao 15.

Como forma de acompanhar as leituras realizadas pelos alunos, os professores devem propor um registro de leitura. A professora dessa classe de quinto ano propôs aos alunos o registro de leitura por meio de book reviews. Assim, logo no início do ano letivo, ela indicou o conteúdo e o formato pelo qual esse registro deveria ser realizado. Quanto ao conteúdo, a resenha devia conter o título do livro, o nome do autor, o gênero textual (basicamente ficção ou não-ficção), um resumo da história lida, comentários pessoais sobre o que gostaram ou não gostaram sobre a história, e recomendações sobre

\footnotetext{
${ }^{16} \mathrm{O}$ critério de nivelamento é a gradação. Cada nível de leitura é formado por uma determinada coleção de livros. Há diversos exemplares de cada livro, pois pode haver mais de um aluno lendo no mesmo nível e o mesmo livro. O reading scheme vai do nível 01 ao 16 . As assistentes de classe são responsáveis por realizar a troca de livros para os alunos conforme eles finalizam suas leituras.
} 
tipos de leitores que se interessariam pelo livro (por faixa etária, interesse, gênero, entre outros). Quanto ao formato, a instrução da professora indicava que a resenha fosse feita em papel A4, posição paisagem dobrado ao meio, com uma ilustração e título do livro na folha de rosto e o conteúdo na parte interna da folha. No entanto, a professora apresentou tal formato de apresentação como sendo apenas uma sugestão, deixando aberto aos alunos a possibilidade de apresentarem os book reviews em outros formatos, da forma que quisessem, sem contudo explicar ou exemplificar que formatos seriam estes.

Se por um lado a instituição se preocupa com a competência estritamente linguística em relação à leitura (fluência, entonação, pronúncia ${ }^{17}$, decodificação de palavras, relação das palavras nas frases e destas no texto, etc) e seu registro (resumo do livro para certificação que a leitura foi cumprida), como indica o nivelamento gradual de leitura, por outro, a pesquisa buscou chamar a atenção para as maneiras pelas quais os alunos estavam construindo sentido sobre o que liam.

Desse modo, o primeiro passo para a realização da coleta de dados da pesquisa foi um pedido de autorização, por meio de carta, enviado aos pais. Dos vinte alunos da sala, dezoito participaram da pesquisa. Para fins de análise, os alunos foram identificados como A1 até A18.

Como os alunos produziam um book review para cada livro que liam, durante um período de seis meses o corpus de dados coletados foi bastante extenso e precisou ser selecionado. Em um primeiro momento o material foi tabulado e classificado por temas comuns de leitura (leituras de um mesmo livro ou mesmo nível). Em seguida, os critérios de seleção basearam-se, principalmente, nas escolha de diferentes book reviews acerca de um mesmo livro (não havia muitos) e por níveis de leitura diferentes. Procurou-se também, contrapor leituras de alunos brasileiros e estrangeiros.

\section{LEITURA E CONSTRUÇÃO DE SENTIDOS}

"Meaning is not in the head, but in social practices; and that in acquiring social practices one gets 'deep' meanings 'free'" (Gee 1997, p. 274)

\footnotetext{
${ }^{17}$ Parte da leitura dos livros é realizada em voz alta com o acompanhamento da assistente de classe. Estas são também responsáveis por checar o entendimento da leitura realizada pelos alunos por meio de perguntas sobre as histórias dos livros lidos.
} 
Como discutido acima, os estudos do letramento crítico têm evidenciado a importância de uma educação que esteja engajada em mudanças sociais e interessada na diversidade cultural. Os teóricos Luke e Freebody (1997) afirmam que nas últimas décadas houve um interesse crescente sobre o letramento crítico por parte de educadores, contudo sua prática ainda tem sido relacionada a currículos e modos tradicionais de educação que não favorecem as necessidades locais em projetos educacionais. Ao contrário, esses estudiosos acreditam que o letramento crítico deva valorizar práticas que respeite novas formas de construção de conhecimento e de meaning making.

A noção de meaning making pode ser remetida à Gee (1997) e se relaciona com aprender a situar (construir) significados. Para este autor, meaning making é um processo pelo qual o aluno desenvolve uma percepção crítica da interpretação dos eventos em sua vida em relação ao mundo a sua volta. Dessa forma, o significado que o indivíduo chega após a leitura de uma história ou ter assistido à um filme, por exemplo, é mediado por suas experiências sociais, culturais e históricas. Em muitos casos, quando os alunos se engajam no processo de representar seus interesses, eles transformam significados estagnados, fixos e 'naturalmente' impostos na sociedade.

$\mathrm{Na}$ pesquisa em questão, as análises das resenhas dos alunos buscaram interpretar como eles se posicionavam epistemologicamente diante dos livros que liam e da maneira como escreviam as resenhas obrigatórias. De modo geral, os alunos cumpriam sem muitos questionamentos a tarefa escolar a eles atribuída, sendo que a maioria dos alunos liam os livros propostos e realizavam as resenhas solicitadas regularmente - essa questão será expandida a seguir. A escola, por sua vez, tinha a preocupação central com o desenvolvimento da fluência de leitura do aluno, principalmente, a partir da quantidade de leitura realizada ${ }^{18}$. No entanto, esses alunos criavam significados a respeito das histórias lidas, relacionavam-se com o que liam ora gostando ou se identificando com a leitura, ora não entendendo muito bem ou não achando muito sentido no que liam. Ao realizar as resenhas sobre as leituras, alguns alunos apenas cumpriam, a sua maneira, a tarefa solicitada. Outros alunos, encontravam ali a possibilidade de expor sua opinião a respeito do que liam. Muitos outros, ainda,

\footnotetext{
${ }^{18}$ Essa interpretação advém da experiência de trabalho da pesquisadora que era explicitamente instruída a acompanhar e cobrar o avanço das leituras dos alunos. Ademais, em períodos regulares, a escola realizava um levantamento do nível de fluência de leitura dos alunos, e os apresentavam em gráficos entre a relação faixa etária real X faixa etária de nível de leitura.
} 
extrapolaram no formato de apresentação da resenha (lembrando que essa possibilidade foi oferecida, mas não exigida, pela professora).

Assim, uma das construções de significados a respeito da leitura desses alunos foi quanto ao formato das resenhas apresentadas. Muitas resenhas não se restringiam aos limites da página e da maneira como a professora havia orientado, alguns alunos utilizaram maneiras multimodais para apresentar suas resenhas, ou seja, foram além do formato proposto pela professora e até mesmo, além do papel. No anexo 1, há três exemplos de resenhas que indicam essa extrapolação dos limites da escrita convencional (da esquerda para a direita e de cima para baixo). Na resenha do aluno A5 sobre o livro Fancy a spider for breakfast?, há um cuidadoso trabalho de corta e cola, que transforma seu texto em uma viva resenha em que cada espaço é utilizado para seus comentários a respeito da leitura. A aranha ganha voz, por meio de balões de fala, e suas patas contém informações, tais como nome do aluno, autor e gênero do livro, nível em que o livro se insere, entre outros. A resenha da aluna A3 a respeito do livro Viking Adventure, transforma um elemento da história - o pergaminho do mapa do tesouro - em sua própria resenha. Ela molda a folha de sulfite em um pergaminho, cuidadosamente amassando, picotando as laterais e colorindo o papel. No final, o enrola e o fecha com uma linda fita vermelha. Outro exemplo, é a resenha da aluna A7 sobre o livro Scrapman, que além de apresentar sua resenha em papel como solicitado (não há a imagem dessa resenha), ela constrói um scrapman em 3D, utilizando canos, fita adesiva, e outros materiais. O scrapman em 3D foi apresentado como sendo a ilustração (uma das etapas da resenha solicitada pela professora) do livro que leu.

Podemos traçar os exemplos acima para uma prática que Lankshear e Knobel (2003) denominam de epistemologia da performance. Para esses autores, essa noção é central em uma sociedade cada vez mais digitalizada, pois trata-se de uma epistemologia que prevê que "saibamos agir na ausência de modelos e exemplos" (p.173), ou ainda, saber agir na busca por novos significados, uma prática que permite quebrar regras e inovar. Cabe lembrar, que ao propor o formato das resenhas a professora abriu espaço para os alunos proporem outros formatos, sem contudo, indicar que formatos seriam esses.

Outro aspecto analisado nas resenhas dos alunos refere-se às escolhas dos conteúdos. Apesar das orientações da professora a respeito de quais conteúdos a resenha deveria conter (título do livro, nome do autor, gênero textual, resumo da história, comentários pessoais, e público-alvo), tais indicações não foram estritamente seguidas. 
Um exemplo disso foi a resenha (veja anexo 2) do aluno A5, que incluiu, além do resumo da história, outros tipos de conteúdo em sua resenha, tais como: dicas para leituras adicionais (find out more), lista de personagens, listagem dos livros contidos naquele nível de leitura, uma seção After Reading que sugere aos pais perguntas que possam fazer aos filhos para acompanhar a leitura, indicação de onde encontrar o livro (you search for the library for this book), e ainda, um quiz para o leitor indicar os pontos fortes e fracos do livro, entre outros elementos. Trata-se de um modo bastante criativo de apresentar sua resenha, que revela também um aprendizado das narrativas que vivencia naquela escola - essa questão será expandida a seguir. Observa-se que o elemento visual é também bastante importante para esse aluno.

Outro eixo de análise se deu em relação a diferentes leituras de alunos distintos a respeito de um mesmo livro. Quando diferentes resenhas acerca de uma mesma história foram analisadas, pôde-se observar o que cada aluno valoriza, aprende e apreende como elementos distintos da narrativa, confrontando-os muitas vezes com seus valores e noções de mundo do que consideram "real", ou impossível, ou ainda fantástico, identificando-se ou não com o que se deparam nas histórias lidas. Nesse sentido, maneiras aparentemente tão pessoais de construir as leituras dos textos e apresentar as informações não se referem simplesmente a diferenças individuais, mas construções formadas pelo meio social desses alunos na maneira como se relacionam com a ficção, na forma de construir sentidos e apresentá-los como texto.

É importante relembrar que o contexto escolar em questão adota um currículo inglês que propõe um esquema de leitura importado (do Reino Unido), em que a classificação da leitura a ser indicada, no caso específico dos reading books, é feita pela competência linguística de cada aluno, o que faz com que, por conta do contexto brasileiro, tais alunos leiam textos escritos para nativos da língua inglesa e para idades inferiores às deles. A partir das resenhas analisadas na pesquisa, foram raras as vezes que os alunos questionaram se as narrativas lhes eram apropriadas ou não. Contudo, foram identificados na resenha do aluno A14, por exemplo, comentários a respeito do livro lido como sendo infantil (babish) o que pode evidenciar uma não aceitação do conteúdo oferecido. Ainda, no caso da aluna A7, ela questiona alguns autores dos textos que lê indicando que "não faz seu tipo de leitura" (it's not my type of reading). Tais exemplos indicam um posicionamento a respeito dos conteúdos lidos, levando com que esses alunos questionem os significados que construíram a respeito das histórias. 


\section{CONSIDERAÇÕES FINAIS}

O ensino na perspectiva do letramento crítico requer um entendimento de como as práticas trazidas pelos alunos à sala de aula são recursos culturais e não diferenças idiossincráticas individuais, estilos de aprendizado ou déficits de habilidade. Uma consequência crítica seria que tais recursos culturais são conectados e transformados por influências econômicas e políticas, que influenciam várias esferas (pública, privada, e outras) da vida desde o acesso ao emprego até a participação religiosa ou política.

No contexto da pesquisa, os procedimentos para o desenvolvimento da leitura da escola (escolha de livros, de atividades de leitura, classificação de nível de leitura em função de faixa etária e de competência linguística individual) fazem parte da proposta de letramento daquela instituição, tornando os livros de leitura uma tarefa diária a ser cumprida, uma lição de casa. Ao compreenderem tais procedimentos em seu habitus, grande parte dos alunos apreende uma instrução implícita de que não é papel deles questionar a proposta de desenvolvimento de leitura, o conteúdo dos livros, a classificação desses, etc, embora alguns façam, a seu modo, esse questionamento. Destarte, é relevante considerar que boa parte da interpretação desses alunos revela um aprendizado da escola, segundo o qual o aluno deve desenvolver certas habilidades juntamente com a leitura, como síntese, concisão, 'clareza', que os personagens têm características ou personalidades que os qualificam e que essas características devem ser identificadas pelo leitor. De modo que ao mesmo tempo em que constroem suas leituras, absorvem marcas interpretativas que imprimem aceitabilidade às suas capacidades de ler e construir sentidos.

Acredito na importância desse trabalho como maneira de (re)pensar e (re)interpretar a prática de leitura na escola e o letramento escolar diante dos desafios da sociedade atual.

\section{REFERÊNCIAS}

ANDRÉ, M. E. D. A. Etnografia da prática escolar. São Paulo: Papirus.

LUKE, A. (1994). The Social Construction of Literacy in the Primary Classroom. Melbourne: Macmillan, 1995.

BAYNHAM, Mike. (2004) Ethnographies of Literacy: Introduction.In: Language and Education, 2004, Vol 18:4. 
CERVETTI, G.; PARDALES, M. J.; DAMICO, J. S. A Tale of Differences: Comparing the Traditions, Perspectives, and Educational Goals of Critical Reading and Critical Literacy, Reading Online, 2001. Disponível em: http://www.readingonline.org/articles/art_index.asp?HREF=article/cervetti/index.html

GEE, J. P. Meanings in discourse: Coordinating and being coordinated in Muspratt, S., Luke, A. \& Freebody, P (Eds.), Constructing Critical Literacies. Cresskill, New Jersey: Hampton Press, 1997.

GEERTZ, C. [1973] A interpretação das culturas. Rio de Janeiro: Zahar, 1978.

LANKSHEAR C. \& KNOBEL M. New Literacies. Changing Knowledge and Classroom Learning. 'Digital epistemologies': Rethinking Knowledge for Classroom Learning. Buckingham, UK: Open University Press, 2003.

LUKE, A.; FREEBODY, P. Shaping the social practices of reading. In: MUSPRATT, S.; LUKE, A.; FREEBODY, P. (Ed.). Constructing critical literacies. St. Leonards, Australia: Allen \& Unwin, 1997.

MENEZES DE SOUZA, L.M.T. Para uma redefinição de Letramento Crítico: conflito e produção de Significacão. Em: Formação de professores de línguas: ampliando perspectivas/ Ruberval Franco Maciel e Vanessa de Assis Araujo (Orgs.) Jundiaí, Paco Editorial, 2011.

THE NEW LONDON GROUP. A pedagogy of multiliteracies: designing social futures. In: COPE, B.; KALANTZIS, M. Multiliteracies. Literacy learning and the design of social futures. London: Routledge, 2000. 


\section{ANEXO 1}

Trabalho do aluno A5 - Título:

Fancy a spider for breakfast?

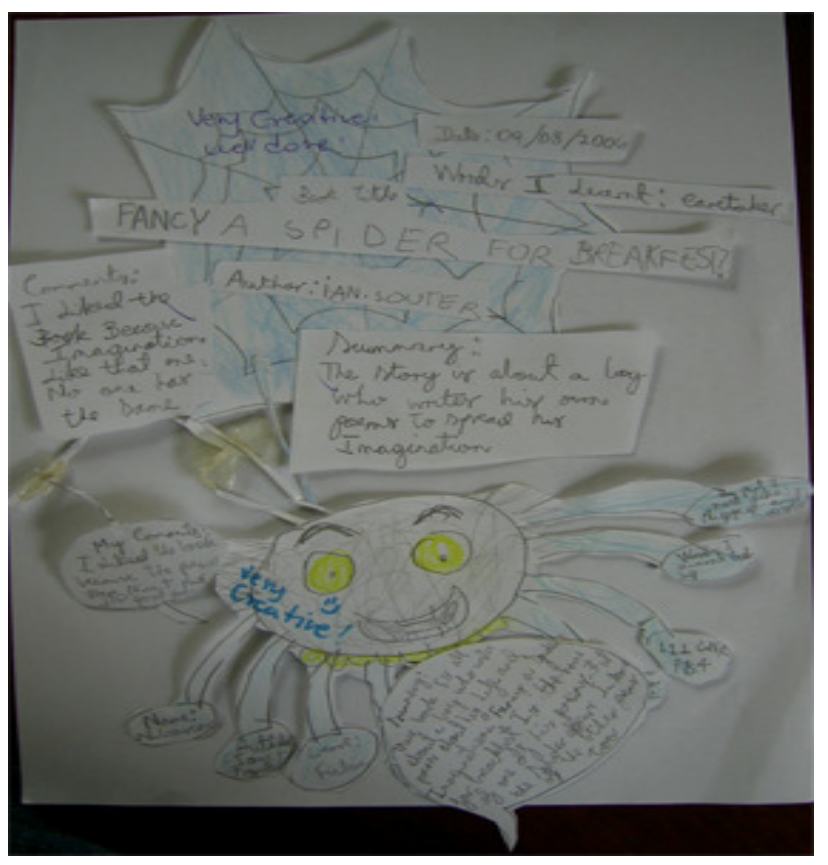

Trabalho da aluna A3 - Título: Viking Adventure
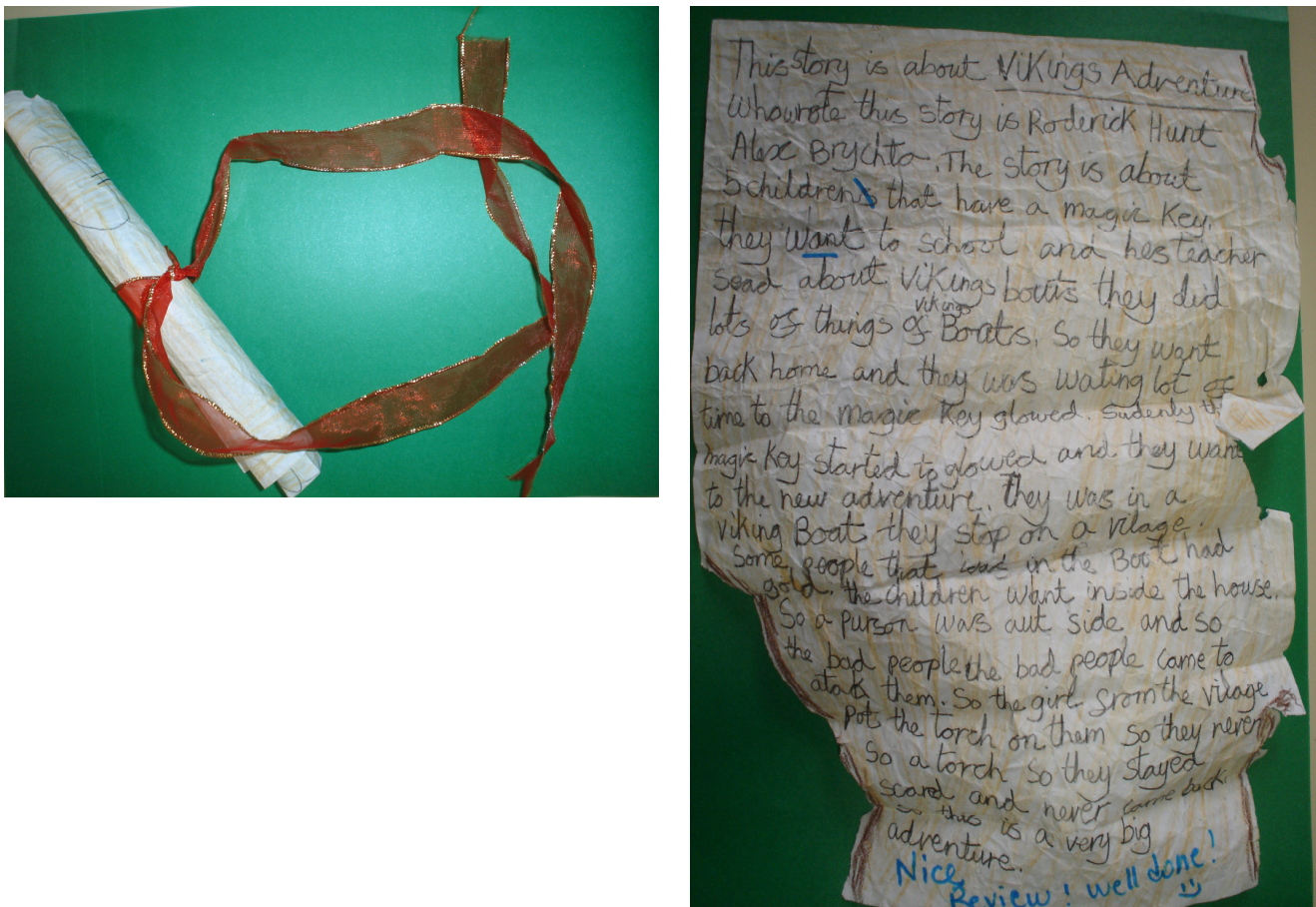
Trabalho da aluna A7 - título:

Scrapman

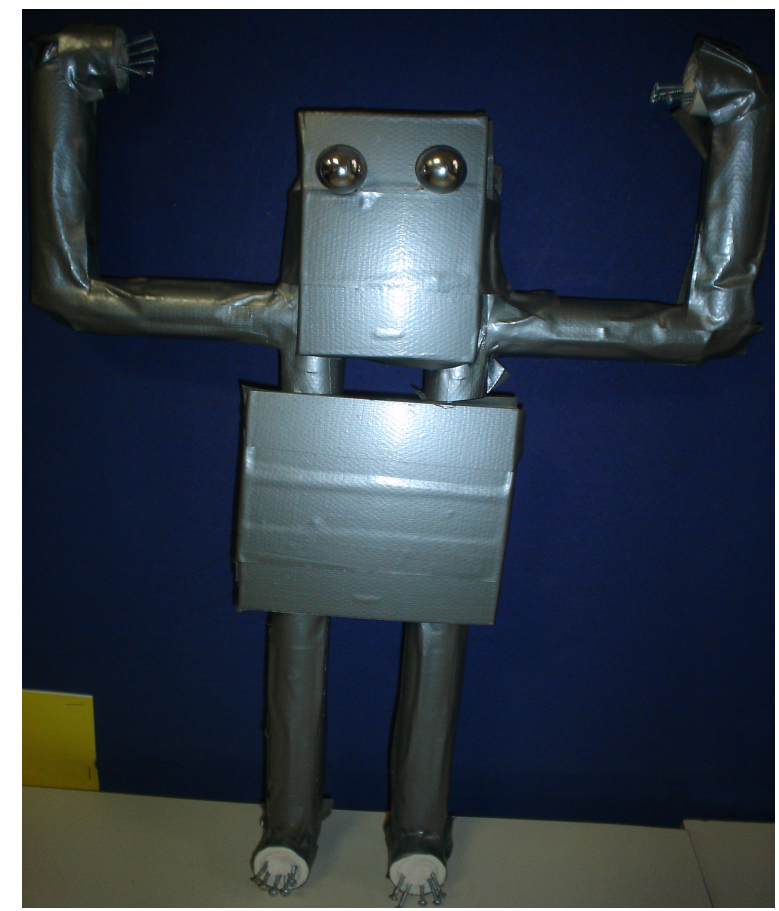

Trabalho do aluno A18 - Título: Kidnappers

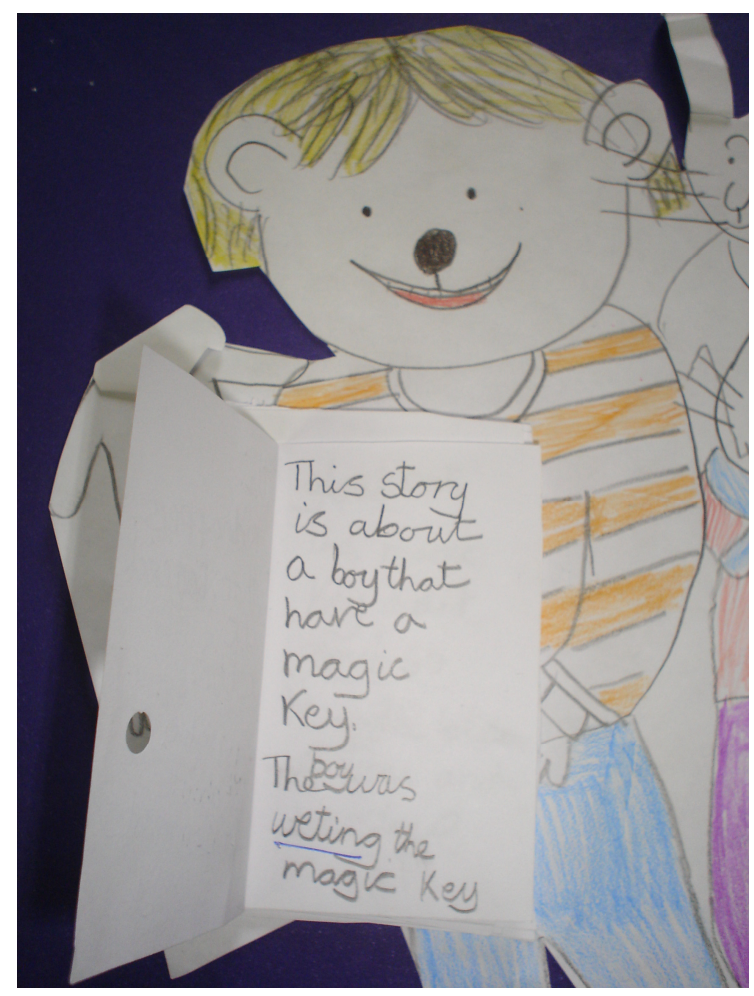




\section{ANEXO 2}

Trabalho do aluno A5 - Título: Billy's Luck
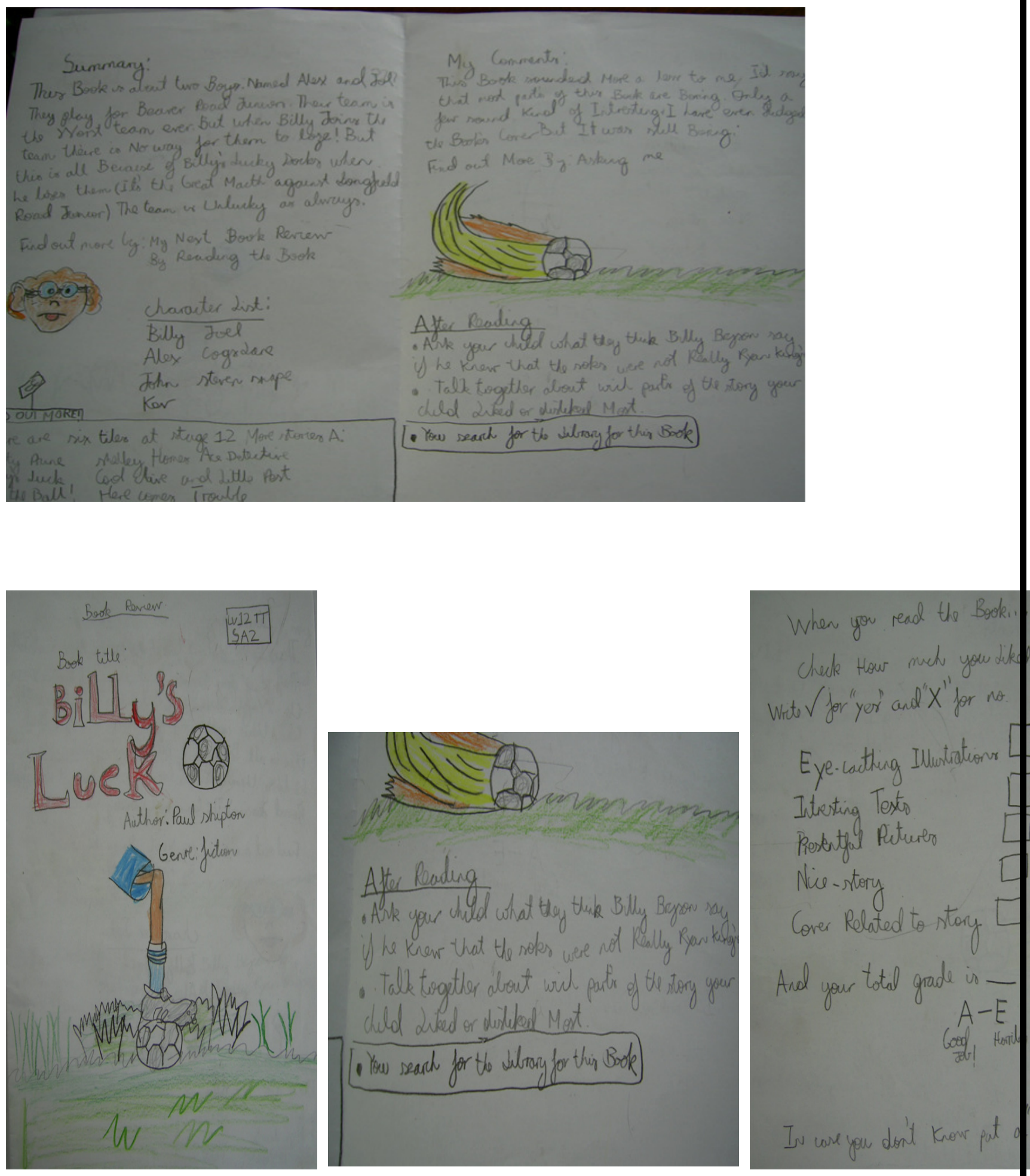